\title{
FOUCAULT: A LOUCURA COMO FIGURA \\ HISTÓRICA E SUA DELIMITAÇÃO NAS PRÁTICAS PSIQUIÁTRICAS E PSICANALÍTICAS
}

Sérgio Bacchi Machado

Psicólogo e mestre pelo Instituto de Psicologia da USP
RESUMO: Percorrem-se algumas linhas do pensamento de Michel Foucault. Tematiza-se o percurso histórico da loucura e a inserção desta em um campo de oposição entre a razão e a desrazão. Destacase a desapropriação, sofrida pela loucura, da possibilidade de falar a verdade de si. Neste sentido, a criação da psiquiatria, nos primórdios do século XIX, caracteriza-se pelo silenciamento moral da loucura; silenciamento este com o qual a psicanálise mais tarde compactua. Em um segundo momento, aborda-se o desenvolvimento histórico da relação médico-paciente enfatizando as práticas psiquiátricas e a contestação destas pela antipsiquiatria.

Palavras-chave: Loucura, história, psiquiatria, psicanálise, Foucault.

ABSTRACT: Foucault: madness as a historic figure and its delimitation in psychiatric and psychoanalytical practices. The aim of this article is to explore Michel Foucault's thoughts through the historic course of madness and its insertion in a field of opposition between reason and non-reason. The deprivation that affected madness in relation to its possibility of expressing the truth about itself is highlighted here. In that sense, the creation of psychiatry in the early XIX century is featured by the moral silence of madness which psychoanalysis will be in agreement with later on. Then, the historic development of the relationship between the doctor and the patient emphasizing the psychiatric practices and their contestation by anti-psychiatry is approached.

Keywords: Madness, history, psychiatry, psychoanalysis, Foucault. 


\section{LOUCURA E PSICANÁLISE}

Em A história da loucura na idade clássica, obra originalmente publicada em 1961, Foucault (2002) aborda a transfiguração histórica da loucura em doença mental. Para tanto, ele demonstra como a concepção de alienação mental de cunho psiquiátrico pode ser revista por uma arqueologia da loucura no Ocidente - do Renascimento à modernidade. A loucura constrangida ao domínio médico e identificada à enfermidade mental é descortinada pela arqueologia foucaultiana como fenômeno recente. A constituição de um espaço terapêutico específico, os asilos, para curar os agora denominados 'doentes', é o correlato do processo histórico que criou a alienação mental.

A formação da psiquiatria nos primórdios do século XIX é marcada em sua base de sustentação por estes eventos que, mesmo sendo uma ruptura com outras práticas - a loucura jamais teve até então o estatuto de enfermidade mental —, só podem ser compreendidos do ponto de vista histórico. Um longo percurso foi necessário para que a disciplina psiquiátrica detivesse o saber sobre a loucura. A bem dizer, a psiquiatria nasce no início do século XIX, justamente no momento em que passa a deter o conhecimento da loucura, emitindo enunciados sobre a doença mental, exercendo domínio e incidindo sobre novas práticas sociais. Foucault evidencia este trajeto desde os primórdios da Idade Clássica e demonstra de que maneira foram dadas as condições de possibilidade para o surgimento da disciplina psiquiátrica no Ocidente. Ele faz com que nos debrucemos sobre a trajetória histórica da loucura desde a Renascença a fim de compreender a transformação que se operou.

Para o autor, a loucura atravessa, na tradição ocidental, um processo de desqualificação de sua potencialidade de dizer a verdade. Tal depreciação da loucura está articulada a um processo amplo na história do Ocidente, marcado pela oposição radical dos registros da razão e da desrazão. Neste sentido, a desqualificação da loucura - a qual ocupava posição estratégica neste embate (BIRMAN, 2000) — é marca incontestável do triunfo da razão sobre a desrazão que se operou no Ocidente. ${ }^{1}$ Uma vez expulsa a loucura do registro da razão, o único reconhecido como detentor da verdade na modernidade, aquela perde, instantaneamente, a possibilidade de ser escutada.

Com efeito, o campo da razão passa a ser o único qualificado a "dizer" qualquer coisa. Dessa forma, sendo a história da loucura o processo de produção da doença mental, ela é ao mesmo tempo a história da "suspensão da loucura como linguagem proscrita” (FOUCAULT, 1972, p.579). Este movimento

\footnotetext{
${ }^{1}$ Foucault nos demonstra que a constituição da loucura como outro da razão — ou ausência da razão — deve ser remontada à filosofia do sujeito inaugurada por Descartes. Efetivamente a metafísica cartesiana funda o sujeito no autocentramento da substância pensante, destacando assim o eixo da razão como base exclusiva para a positivação do sujeito.
} 
corresponderia a uma alteração drástica da cena social que compõe a loucura. Efetivamente, nos primórdios do século XVII a loucura passa por uma restrição/ exclusão da cena social, sendo confinada junto a outras figuras da marginalidade nos hospitais gerais. Este processo de tentativa de expulsão da loucura não só do registro razão-verdade como também de toda cena social possível, culmina na criação, pela nascente psiquiatria do século XIX, dos asilos para os alienados. O asilo torna-se um espaço diferenciado para o trato exclusivo do doente mental, em oposição à circulação mais livre e trágica da loucura no Renascimento. Segundo Birman:

“(...) foi no espaço dessa oposição axial, isto é, no campo imantado entre razão e desrazão, que Foucault inscreveu a sua leitura arqueológica sobre a loucura, segundo a qual a transformação recente desta enfermidade mental seria, na modernidade, o apogeu desse longo percurso na cultura ocidental." (BIRMAN, 2000, p.36)

História da loucura na idade clássica rompe com uma tradição de pensamento consagrada por historiadores da psiquiatria (e de outras áreas também). A doença mental passa a ser uma entidade "produzida" e não uma verdade descoberta. Com Foucault, a história não segue mais uma linha contínua em direção a um conhecimento cada vez mais perfeito e independente dos elementos sociais que o circunscrevem. Ela não é animada por um princípio de coesão ou por uma teleologia a que sempre deve retornar. ${ }^{2}$ Pelo contrário,

"quis o destino, infelizmente, que as coisas fossem mais complicadas. E, de um modo geral, que a história da loucura não pudesse servir, em caso algum, como justificativa e ciência auxiliar na patologia das doenças mentais. A loucura, do devir de sua realidade histórica, torna possível, em um dado momento, um conhecimento da alienação num estilo de positividade que a delimita como doença mental, mas

\footnotetext{
${ }^{2}$ Saindo um pouco do âmbito específico da loucura, o seguinte trecho de $A$ arqueologia do saber é exemplar da crítica foucaultiana à história como continuidade e à sua outra face, a filosofia do sujeito:

"Se a história do pensamento pudesse permanecer como o lugar das continuidades ininterruptas, se ela unisse, continuamente, encadeamentos que nenhuma análise poderia desfazer sem abstração, se ela tramasse, em torno do que os homens dizem e fazem, obscuras sínteses que a isso se antecipam, o preparam e o conduzem, indefinidamente, para seu futuro, ela seria, para a soberania da consciência, um abrigo privilegiado. A história contínua é o correlato indispensável à função fundadora do sujeito: a garantia de que tudo que lhe escapou poderá ser devolvido; a certeza de que o tempo nada dispersará sem reconstituí-lo em uma unidade recomposta; a promessa de que o sujeito poderá, um dia — sob a forma da consciência histórica - , se apropriar, novamente, de todas essas coisas mantidas à distância pela diferença, restaurar seu domínio sobre elas e encontrar o que se pode chamar sua morada." (FOUCAULT, 2004, p.14.)
} 
não é este conhecimento que forma a verdade desta história, animando-a secretamente desde sua origem." (FOUCAULT, 2002, p.119)

Assim, a objetividade não pode ser uma transparência que fala, de forma asséptica e desinteressada, a verdade da loucura:

"na realidade, ela [a objetividade] só se oferece exatamente àquele que está protegido dela. O conhecimento da loucura pressupõe, naquele que a apresenta, uma certa maneira de desprender-se dela, de antecipadamente isolar-se de seus perigos e de seus prestígios, um certo modo de não ser louco. E o advento histórico do positivismo psiquiátrico só está ligado à promoção do conhecimento de uma maneira secundária; originalmente, ele é a fixação de um modo particular de estar fora da loucura: uma certa consciência de não-loucura que se torna, para o sujeito do saber, situação concreta, base sólida a partir da qual é possível conhecer a loucura." (FOUCAULT, 2002, p.445)

Dessa forma, Foucault vê a gênese da doença mental como uma tentativa da razão de conjurar o perigo que lhe é interior, de reduzir a alteridade que a observa de dentro. Cabe ressaltar que o autor estava próximo ainda de uma orientação fenomenológica e de uma concepção de experiência “original” da loucura: "De maneira geral, 'Histoire de la folie' dedicava uma parte bastante considerável, e aliás bem enigmática, ao que se designava como 'experiência', mostrando, assim, o quanto permanecíamos próximos de admitir um sujeito anônimo e geral da história” (FOUCAULT, 2004, p.18). Sem dúvida, a orientação metodológica seguida em sua obra sobre a loucura será criticada por ele em um momento posterior. É o que verificamos no seguinte trecho de 1969:

“Não se procura reconstituir o que podia ser a própria loucura, tal como se apresentaria inicialmente em alguma experiência primitiva, fundamental, surda, apenas articulada, e tal como teria sido organizada em seguida (traduzida, deformada, deturpada, reprimida talvez) pelos discursos e pelo jogo oblíquo, frequentemente retorcido, de suas operações. Sem dúvida, semelhante história do referente é possível; não se exclui de imediato o esforço para desenterrar e libertar do texto essas experiências 'pré-discursivas'. Mas não se trata, aqui, de neutralizar o discurso, transformá-lo em signo de outra coisa e atravessar-lhe a espessura para encontrar o que permanece silencioso aquém dele, e sim, pelo contrário, de mantê-lo em sua consistência, fazê-lo surgir na complexidade que lhe é própria. Em uma palavra, quer-se, na verdade, renunciar às 'coisas', 'despresentificá-las'; conjurar sua rica, relevante e imediata plenitude, que costumamos considerar como a lei primitiva de um discurso que dela só se afastaria pelo erro, esquecimento, ilusão, ignorância 
ou inércia das crenças e das tradições ou, ainda, desejo inconsciente, talvez, de não ver e de não dizer; substituir o tesouro enigmático das 'coisas' anteriores ao discurso pela formação regular dos objetos que só nele se delineiam (...)” (FOUCAULT, 2004, p.53)

Com efeito, Foucault se distanciará a partir de Arqueologia do saber das proposições metodológicas contidas em sua obra sobre a loucura. Ele abandonará sua concepção primeira de experiência original - a qual seria abafada e deturpada pelas diversas coerções - para enfatizar a produção dos objetos no interior da ordem do discurso. Isso não impede, porém, que ele demonstre já em História da loucura como o conhecimento objetivo jamais é orientado por uma suposta neutralidade do saber. Foucault, pensador que posteriormente afirmará com todas as letras a intencionalidade não subjetivista do poder, faz ver que a ciência da loucura almeja sobretudo uma demarcação de dois campos que só podem existir em uma mútua determinação. O primeiro, caracterizado pela razão e legitimado por sua oposição à loucura. O segundo, marcado pela desrazão e deslegitimado pela razão que a exclui. Um campo só se configura com referência ao outro e, no entanto - ou talvez por isso mesmo - , são ao mesmo tempo estrategicamente autoexcludentes. Por este viés, falar cientificamente sobre a loucura equivale a, em essência, situar-se em sua exterioridade.

É justamente a problemática do conhecimento que aparece como moldura a um questionamento subjacente à arqueologia foucaultiana da loucura. Mais tarde, quando Foucault abordar a analítica do poder, a controversa tensão conhecimento-loucura será colocada em xeque outra vez. O que se aventará então é a possibilidade de vínculos com a loucura que ultrapassem a vontade de saber que tende a domesticá-la:

“E, no mesmo instante se encontra aberto o problema da eventual libertação da loucura em relação a esta forma singular de poder-saber que é o conhecimento. É possível que a produção da verdade da loucura possa se efetuar em formas que não sejam as da relação de conhecimento? Problema fictício, dirão, pergunta que só tem seu lugar numa utopia. De fato ela se coloca concretamente todos os dias a propósito do papel do médico, do sujeito depositário do estatuto do conhecimento, no trabalho de despsiquiatrização." (FOUCAULT, 2001, p.128)

Nesse sentido, nem mesmo a psicanálise, segundo Foucault, consegue relacionar-se simetricamente com a loucura, uma vez que:

“ela [a psicanálise] revestiu o olhar absoluto do vigilante com a palavra indefinidamente monologada do vigiado — conservando assim a velha estrutura asilar do olhar 
não recíproco, porém equilibrando-o, numa reciprocidade não simétrica, através da nova estrutura da linguagem sem resposta." (FOUCAULT, 2002, p.482)

A crítica foucaultiana, assim, não se restringe ingenuamente ao autoritarismo ostentado pelo psicanalista. Caso fosse isso, bastaria que os psicanalistas se tornassem pessoas melhores e uma correção técnica fosse empreendida para que esta crítica fosse desarmada e o problema, resolvido. Pelo contrário, o que está na mira precisa de Foucault é a adequação da produção da verdade a uma relação de poder marcada em seu fundamento pela assimetria. É isto que está em questão quando nos deparamos com sua apreciação cáustica da regra fundamental da psicanálise. Utilizando-se da ironia como procedimento retórico, Foucault chama de "liberdade discursiva" ao efeito de anulação do analisando levado a cabo pelo dispositivo psicanalítico:

\footnotetext{
“Regra da liberdade discursiva — 'você não vai poder mais se gabar de enganar o médico, pois você não vai responder a perguntas; você dirá tudo o que lhe vem à cabeça sem que tente mesmo me perguntar o que penso disto, e se você quiser me enganar infringindo esta regra, não serei enganado realmente. E você terá caído no ardil já que terá perturbado a produção da verdade e só terá acrescentado algumas sessões à soma que me deve."” (FOUCAULT, 2001, p.125).
}

\section{LOUCURA E (ANTI)PSIQUIATRIA}

Em A casa dos loucos, texto publicado originalmente em 1975, Foucault se detém no exame do surgimento da antipsiquiatria. Para tanto, retoma o processo histórico que configurou a relação de poder médico-paciente a partir dos hospitais do século XVIII. Refaçamos, então, em linhas sucintas, esse percurso foulcaultiano. Antes, contudo, uma ressalva que, de tão fundamental, talvez seja desnecessária: nosso olhar sobre este texto é deslocado para pontos específicos, ou seja, nossa leitura é interessada. Com efeito, privilegiamos alguns encadeamentos históricos específicos que culminaram na criação da antipsiquiatria em detrimento de outros aspectos também centrais da "casa dos loucos".

O hospital no século XVIII era um lugar de manifestação da doença. Ao médico cabia o exercício de uma ação direta sobre ela de tal forma que permitisse a eclosão de sua verdade. Ele deveria invocar e criar as condições para a doença desenvolver todas as suas potencialidades intrínsecas e libertar-se de formas confusas e misturadas a outras doenças. Para isso, era necessário atocaiá-la e surpreendê-la em rituais e ocasiões privilegiados. Portanto, a relação médicopaciente de então era pautada por procedimentos de apreensão e produção tratava-se de apanhar a verdade da doença em uma situação específica ocasionada 
pelo médico. A ação terapêutica encontraria aí sua possibilidade de exercício. A concepção de crise, noção médica presente até o final do século XVIII, é exemplar dessa dimensão:

"A crise, tal como era concebida e exercida, é precisamente o momento em que a natureza profunda da doença sobe à superfície e se deixa ver. É o momento em que o processo doentio, por sua própria energia, se desfaz de seus entraves, se liberta de tudo aquilo que o impedia de completar-se e, de alguma forma, se decide a ser isto e não aquilo, decide o seu futuro - favorável ou desfavorável. Movimento em certo sentido autônomo, mas do qual o médico pode e deve participar. Este deve reunir em torno dela todas as conjunções que lhe são favoráveis e prepará-la, ou seja, invocá-la e suscitá-la. Mas deve também colhê-la como se fosse uma ocasião, nela inserir sua ação terapêutica e combatê-la no dia mais propício. Sem dúvida, a crise pode ocorrer sem o médico, mas se este quiser intervir, que seja segundo uma estratégia que se imponha à crise como momento de verdade, pronta a subrepticiamente conduzir o momento a uma data que seja favorável ao terapeuta. No pensamento e na prática médica, a crise era ao mesmo tempo momento fatal, efeito de um ritual e ocasião estratégica." (FOUCAULT, 2001, p.114)

No entanto, o hospital era também o local por excelência da ambiguidade. Uma outra figura protagonizava alianças e duelos imprecisos na noite das práticas hospitalares. De fato, junto à dimensão produtiva, outra perspectiva atravessava a relação médico-paciente: o conhecimento. Ao médico cabia conhecer a doença, para coagi-la a apresentar-se. A doença era suscitada para que pudesse ser desvelada em sua verdade. As espécies de doenças precisavam ser contempladas pelo olhar médico que as categorizava.

“As grandes estruturas hospitalares instauradas no século XIX tomaram para si durante muito tempo esta dupla função. E durante um século (1760-1860) a prática e a teoria da hospitalização, e de uma forma geral a concepção de doença, foram dominadas por esse equívoco: o hospital, estrutura de acolhimento da doença, deve ser um lugar de conhecimento ou um lugar de prova."3 (FOUCAULT, 2001, p.119)

Coerção mútua que envolvia a produção da verdade nos hospitais até o final do século XVIII. Práticas de constatação da verdade, que deveria ser desvelada ao olhar atento do médico conhecedor; e, ao mesmo tempo, rituais do aconte-

${ }^{3} \mathrm{O}$ termo 'prova' é aqui empregado por Foucault em alusão a rituais jurídicos marcados pelo desafio entre acusador e acusado. Em tais rituais, a verdade era o efeito produzido pela determinação do vencedor. Assim, 'prova', no trecho citado, refere-se a ocasiões de manipulação da produção da verdade. 
cimento-verdade que deveria ser suscitado pelo médico astucioso. No hospital, a determinação dupla dessas práticas não era uma contradição, era seu modo possível de ser. Não se trata de uma etapa do conhecimento que, orientado pela razão, pôde superar-se em direção a uma forma em que a ciência atual pudesse enfim se reconhecer. O que está em pauta é antes um outro equilíbrio na distribuição entre poderes e saberes. A relação de poder médico-paciente envolvia, então, modos de sujeição que não mais podemos reconhecer integralmente em nós; e isso não equivale a afirmar de forma peremptória que estamos diante do progresso da objetividade científica. Assim, por meio de um saber crítico, Foucault se esquiva de cometer essa ilusão retrospectiva tão frequente nos historiadores da medicina.

Circunscritos a este duplo constrangimento, uma série de questionamentos e debates acalorados foram suscitados e, de repente, recolheram-se para a sombra. Questionamentos que envolviam o curso de uma doença normal — deveria levar à morte ou à cura ao término de sua evolução? Debates abrangendo a natureza pura ou complexa da doença — haveria apenas uma doença fundamental que se ramificaria em várias outras impuras ou, ao contrário, categorias irredutíveis de doenças? Enfim, um regime discursivo que ruiu com a imposição de um novo personagem na cena hospitalar. Curiosamente, toda comoção causada por sua aparição abrupta e imprevista foi na mesma hora abafada pelo silêncio de seus gestos precisos e econômicos:

"Sabemos bem que a biologia de Pasteur simplificou prodigiosamente todos estes problemas. Determinando o agente do mal e fixando-o como organismo singular, permitiu que o hospital se tornasse um lugar de observação, de diagnóstico, de localização clínica e experimental, mas também de intervenção imediata, ataque voltado para a invasão microbiana." (FOUCAULT, 2001, p.119)

E ainda:

“O lugar onde se produzirá a doença será o laboratório, o tubo de ensaio. Mas aí a doença não se efetua numa crise. Reduz-se seu processo a um mecanismo que pode ser aumentado, e se a coloca como fenômeno verificável e controlável. O meio hospitalar não tem mais que ser para a doença o lugar favorável para um acontecimento decisivo. Ele permite simplesmente uma redução, uma transferência, um aumento, uma constatação. A prova se transforma em teste na estrutura técnica do laboratório" (FOUCAULT, 2001, p.119-120)

Com isso, toda uma tecnologia da verdade foi expulsa das práticas hospitalares e deu lugar a novas formas de sujeição e a novos esquemas de conhecimento. 
A verdade passou a ser conhecida pela mediação de instrumentos e não mais foi atraída e apanhada por armadilhas engenhosas. Desarmado de seus antigos poderes, o médico viu a esfera do conhecimento científico ganhar força em suas práticas. Dentre seus méritos, impôs de repente a competência em detrimento da astúcia. De certo modo, em consonância com suas mãos, que passaram a ser acusadas de transmissoras do mal, a verdade — antes suscitada e invocada precisou ser esterilizada. Justamente lá onde os médicos se viam como argutos produtores da verdade crítica da doença, lá onde sua presença era mais fundamental do que em qualquer outro lugar, justamente lá eles foram colocados contra a parede e feridos de morte: suas mãos, longe de salvarem, traziam a própria doença em sua forma invisível ao paciente. Uma nova assepsia na produção da verdade tornou-se necessária a partir daí, e os próprios médicos foram encarregados de levar a cabo esse projeto.

Foucault faz então um corte rápido em sua escritura e desloca seu foco para a problemática da loucura:

"Antes do século XVIII, a loucura não era sistematicamente internada, e era essencialmente considerada como uma forma de erro ou de ilusão. Ainda no começo da idade clássica, a loucura era vista como pertencendo às quimeras do mundo; podia viver no meio delas e só seria separada no caso de tomar formas extremas ou perigosas. Nestas condições compreende-se a impossibilidade do espaço artificial do hospital em ser um lugar privilegiado, onde a loucura podia e devia explodir sua verdade. Os lugares reconhecidos como terapêuticos eram primeiramente a natureza, pois que era a forma visível da verdade; tinha nela mesma o poder de dissipar o erro, de fazer sumir as quimeras. As prescrições dadas pelo médico eram de preferência a viagem, o repouso, o passeio, o retiro, o corte com o mundo vão e artificial da cidade. Esquirol ainda considerou isto quando, ao fazer os planos de um hospital psiquiátrico, recomendava que cada cela fosse aberta para a vista de um jardim." (FOUCAULT, 2001, p.120-121)

Com o internamento do doente mental no século XIX, a loucura passou a ser distinguida como "desordem na maneira de agir, de querer, de sentir paixões, de tomar decisões, de ser livre” (2001, p.121). O que estava em questão era menos o julgamento perturbado do que uma conduta irregular; menos o erro da razão - concepção esta que nos remete diretamente à Idade Clássica, que unia a loucura a outras figuras da marginalidade (FOUCAULT, 2002) - do que um descontrole das paixões. Neste cenário, o asilo se aproximou do hospital do século XVIII, ou seja, nele a loucura deveria se desenvolver em toda a sua plenitude. Mas não bastava desmascarar a doença mental, era preciso que o asilo fosse o local de confrontação de duas vontades. De um lado, o doente, cuja vontade e 
conduta se (des) caracterizavam pela perturbação e pela irregularidade; por outro, o médico, cuja retidão da índole deveria prevalecer ao término do embate. Tratava-se de sobrepujar os arroubos loucos e colocar "no devido lugar" o caráter do paciente. Imposição de uma vontade sobre a outra num embate travado no solo da ordem moral. ${ }^{4}$

“Assim se estabelece a função muito curiosa do hospital psiquiátrico do século XIX: lugar de diagnóstico e de classificação, retângulo botânico onde as espécies de doenças são divididas em compartimentos cuja disposição lembra uma vasta horta. Mas também espaço fechado para um confronto, lugar de uma disputa, campo institucional onde se trata de vitória e submissão. O grande médico do asilo — seja ele Leuret, Charcot ou Kraepelin - é ao mesmo tempo aquele que pode dizer a verdade da doença pelo saber que dela tem, e aquele que pode produzir a doença em sua verdade e submetê-la, na realidade, pelo poder que sua vontade exerce sobre o próprio doente." (FOUCAULT, 2001, p.122)

Em oposição ao hospital, no qual a função do médico como produtor da verdade diluía-se numa estrutura de conhecimento, no asilo essa função se intensificava ao extremo. Mas isto ocorreu em uma época em que o saber médico precisava se inscrever em um registro que destacasse o conhecimento e a constatação de fenômenos. O psiquiatra, como médico que era, deveria fundamentar suas práticas em seu conhecimento. A condição de médico do psiquiatra o pressionava a se enquadrar nos limites de ação praticados pela medicina pós-pasteuriana. Em outras palavras, o poder que o asilo proporcionava ao psiquiatra deveria ser inscrito em um discurso integrado à linguagem e ao saber médico exigidos então. ${ }^{5}$ A cumplicidade entre essas duas prerrogativas se fez de forma curiosa, de modo que a relação psiquiatra-paciente veio a ser estratégica na criação de uma nova sensibilidade:

"O ponto de perfeição, miraculosa em demasia, foi atingido quando as doentes do serviço de Charcot, a pedido do poder-saber médico, se puseram a reproduzir uma

${ }^{4}$ A esse respeito, ver também Foucault (2002) e Birman (1978).

5 "Como se sabe, a psiquiatria sempre se encontrou em posição incômoda no campo da medicina, pois pretendendo ser uma especialidade médica nunca conseguiu se fundamentar com os saberes advindos da racionalidade médica. O discurso da anatomoclínica, base epistemológica da dita medicina científica, não encontrava legitimidade no campo da psiquiatria. A psiquiatria buscava as causas físicas dos distúrbios mentais e apenas encontrava, desde Pinel e Esquirol, as causas morais. Em contrapartida, o tratamento moral era a base da terapêutica psiquiátrica — em níveis individual e institucional —, que se afastava então de maneira decisiva dos cânones do saber médico. Enfim, a psiquiatria era uma falsa medicina, uma pseudomedicina, já que não se fundamentava nos saberes que fundavam a medicina." (BIRMAN, 2003, p.180-181) 
sintomatologia calcada na epilepsia, isto é, suscetível de decifração, conhecida e reconhecida nos termos de uma doença orgânica." (FOUCAULT, 2001, p.123)

Para Foucault, a primeira enunciação incipiente do movimento que viria a se instaurar como antipsiquiatria ${ }^{6}$ surgiu com a crítica de que Charcot produzia abusivamente a própria realidade da doença, e não sua verdade crítica. Tratava-se de questionar o poder médico em si, mais até do que o conhecimento e a ciência médica. Se a tensão verdade invocada-produzida/descoberta-conhecida precisou ser diluída com a inserção do discurso médico no registro da cientificidade, tratava-se agora de ocasionar abalos na psiquiatria com o questionamento dos fundamentos da relação de poder médico-paciente. “A partir daí creio que se pode compreender o que está em jogo na antipsiquiatria, e que não é absolutamente o valor da verdade da psiquiatria em termos de conhecimento, de precisão do diagnóstico ou de eficácia terapêutica” (FOUCAULT, 2001, p.126).

Desse modo:

“As relações de poder constituíam o a priori da prática psiquiátrica. Elas condicionavam o funcionamento da instituição asilar, aí distribuíam as relações entre os indivíduos, regiam as formas de intervenção médica. A inversão característica da antipsiquiatria consiste ao contrário em colocá-las no centro do campo problemático e questioná-las de maneira primordial.” (FOUCAULT, 2001, p.127)

\section{ARREMATE}

A polêmica figura da loucura ocupa uma posição estratégica na obra de Foucault. Por meio de sucessivos deslocamentos e deslizamentos, ele incide sobre a questão da loucura por ângulos inusitados e sempre surpreendentes. Mais do que proporcionar um novo conhecimento acerca da loucura, Foucault empreende, por meio de sua arqueologia, um rico diálogo com a Psicanálise e a História.

Através de seu método arqueogenealógico, a história passa a ser compreendida por Foucault não mais como uma série de evoluções e contratempos rumo a um saber que, em última instância, estaria destinado à plenitude de uma iluminação total. Assim, a história deixa de ser tomada como a personificação de uma verdade que, por meio de um golpe de força da consciência, seria descortinada e apreendida. Pelo contrário, ela torna-se o campo material no qual uma densa rede de relações de poder configura o solo instável sobre o qual o ser humano se ergue e se constitui.

\footnotetext{
${ }^{6}$ Foucault inclui no movimento da antipsiquiatria uma gama de autores tais como Bernheim, Laing, Basaglia e Cooper.
} 
A psicanálise, por sua vez, encontra-se irremediavelmente imersa nesse campo de estratégias beligerantes. Fazendo alianças, rupturas, cumplicidades e deserções, a psicanálise se cria em um território histórico que a ultrapassa. Sem dúvida, ela é uma interlocutora preciosa do inquieto pensamento foucaultiano (BIRMAN, 2000). Como, de que modo e que papel a psicanálise exerceu na epopeia da vontade de verdade que presidiu a constituição histórica da psiquiatria e a domesticação da loucura? É uma questão que qualquer psicanálise orientada por princípios éticos não pode se furtar a enfrentar. Gostaríamos de pensar que o presente artigo coloca alguns elementos para a meditação desta questão.

Recebido em 13/8/2007. Aprovado em 15/8/2008.

\section{REFERÊNCIAS}

BIRMAN, J. (1978) A psiquiatria como discurso da moralidade. Rio de Janeiro: Graal.

. (2000) Entre o cuidado e o saber de si: sobre Foucault e a psicanálise. Rio de Janeiro: Relume Dumará.

. (2003) Mal-estar na atualidade. Rio de Janeiro: Civilização Brasileira.

FOUCAULT, M. (1972) Histoire de la folie à l'âge classique. Paris: Gallimard. . (2001) “A casa dos loucos”. In: Microfísica do poder. Rio de Janeiro: Graal. . (2002) História da loucura na idade clássica. São Paulo: Perspectiva. . (2004) A arqueologia do saber. Rio de Janeiro: Forense.

Sérgio Bacchi Machado

bacchimachado@gmail.com 